\title{
Symptomatic Dystonia: Clinical Profile of 46 Brazilian Patients
}

\author{
Henrique B. Ferraz and Luiz Augusto F. Andrade
}

\begin{abstract}
Dystonia is a syndrome characterized by sustained muscle contraction, provoking twisting and repetitive movements or abnormal postures. It may be classified according to etiology, as idiopathic or symptomatic. We studied 122 Brazilian patients with a dystonic syndrome. Of these, $46(37.7 \%)$ had symptomatic dystonia. The most frequent cause was tardive dystonia $(34.8 \%)$ followed by perinatal cerebral injury $(30.4 \%)$. Other causes were stroke (13.0\%), encephalitis $(6.5 \%)$ and Wilson's disease $(4.3 \%)$. Cranial trauma, mitochondrial cytopathy and psychogenic, were the least frequent causes with one patient in each category. The etiology in two patients could not be established. Perinatal cerebral injury and postencephalitic dystonia were seen in the younger age group, while post-stroke and tardive dystonia were seen in the older age group.
\end{abstract}

RÉSUMÉ: Dystonie symptomatique: profil clinique de 46 patients brésiliens. La dystonie est un syndrome caractérisé par des contractions musculaires soutenues provoquant des mouvements de torsion et des mouvements répétitifs ou des postures anormales. La dystonie peut être classifiée selon l'étiologie comme idiopathique ou symtomatique. Nous avons étudié 122 patients brésiliens atteints d'un syndrome dystonique. Parmi eux, 46 (37.7\%) avaient une dystonie symptomatique. La cause la plus fréquente était la dystonie tardive $(34.8 \%)$, suivie de lésions cérébrales périnatales $(30.4 \%)$. Les autres causes étaient l'accident cérébro-vasculaire (13.0\%), l'encéphalite $(6.5 \%)$ et la maladie de Wilson $(4.3 \%)$. Le traumatisme crânien, la cytopathie mitochondriale et l'origine psychogénique étaient des causes moins fréquentes, avec un patient respectivement dans chaque catégorie. Chez deux patients, l'étiologie n'a pu être déterminée. On retrouvait les lésions cérébrales périnatales et la dystonie post-encéphalitique chez les plus jeunes, alors que les accidents cérébro-vasculaires et la dystonie tardive se retrouvaient chez les plus âgés.

Can.J. Neurol. Sci. 1992; 19: 504-507

Dystonia is a syndrome characterized by sustained muscle contraction, frequently provoking twisting and repetitive movements or abnormal postures.' It may be classified according to body region affected, age of onset and etiology.'

Dystonia may be due to a variety of causes. The etiological classification consists of two main subgroups: idiopathic or primary, and symptomatic or secondary. In idiopathic dystonia no known cause is found and the patient shows no other neurological abnormalities. Symptomatic dystonia, on the other hand, must have either an identifiable cause or additional neurological abnormalities which cannot be ascribed to an unrelated cause.

For proper classification, patients with only dystonic movements or postures and a negative past history, should undergo investigation to find the cause of the disorder. This should include brain CT scan and biochemical tests for Wilson's disease. ${ }^{2}$ The identification of idiopathic or symptomatic dystonia is important since they may have different prognostic and therapeutic implications.

In order to improve our ability to identify symptomatic dystonia and to obtain further details of these patients in our environment, we studied the records of 46 patients with this diagnosis.

\section{Patients and Methods}

We studied the chart records of patients with the diagnosis of dystonic syndrome as defined by the Ad Hoc Committee of the Dystonia Medical Research Foundation.' We excluded the patients under 12 years of age at the time of their first assessment, parkinsonian patients of any etiology, and those where chorea predominated. The patients with inconclusive or incomplete information were also excluded. All the patients had been evaluated in the Movement Disorders Division of Escola Paulista de Medicina or in one of our private practices, from 1982 through 1988.

For perinatal cerebral injury we consider those patients with definitive asphyxic delivery requiring special assistance and those with kernicterus. The inclusion criteria for tardive dystonia were those of Burke et al. ${ }^{3}$

Of the 122 patients collected, 46 fulfilled the diagnostic criteria for symptomatic dystonia, ${ }^{2}$ whereas the other 76 had idiopathic dystonia and are not presented. Sex, age of onset, body distribution of the dystonic movements and etiology of the disorder were noted. Also, a note was made of the patients that showed tremor along with the dystonia.

From the Movement Disorders Division, Department of Neurology and Neurosurgery, Escola Paulista de Medicina, São Paulo, Brazil

Received January 18, 1992. Accepted in final form May 27, 1992.

Reprint requests to: Dr. H.B. Ferraz, Av. Dr. Altino Arantes, 669 Ap. 43, CEP 04042 Sao Paulo, Brazil 


\section{RESULTS}

Of the 46 patients with symptomatic dystonia $337.7 \%$ of the total 122 patients), 40 were seen in an academic institution and 6 in private practice. Twenty-five were male and 21 female. The average age of onset of the dystonia was 22.5 years, with a range of 1 to 61 . Twenty patients had the onset of the disease in infancy or childhood (0-12 years), 3 in adolescence (13-20 years), and 23 in adulthood (after 20 years).

Postural tremor was observed in 9 patients $(19.6 \%)$ examined with outstretched arms and fingers. In one of the patients with postencephalitic dystonia we also observed myoclonic movements.

Table 1 shows the clinical profile of the patients. The body distribution and the average age of each diagnosis are shown. The most common causes of symptomatic dystonia were prolonged use of neuroleptics (34.8\%) and perinatal cerebral injury (30.4\%).

Tardive dystonia (TD) (i.e., dystonic movements due to prolonged use of neuroleptics) occurred mainly in young psychiatric patients who had been under chronic neuroleptic treatment, usually with a combination of these drugs. Cervical and cranial segments were the most commonly areas affected, with 12 and 9 patients respectively, of the 16 TD cases. The average age of onset was about 35 years for TD.

The patients with perinatal cerebral injury and postencephalitic dystonia developed the abnormal movements between the ages of 3 and 4 years. Two of the patients with perinatal cerebral injury developed dystonia 10 years after a complicated delivery. Two other cases resulted from kernicterus. Both of these had generalized dystonia developed at 1 and 3 years of age, respectively. Asphyxic delivery was considered to be the cause of the injury in the other 12 patients.

Two patients with positive family history and low levels of serum ceruloplasmin were diagnosed as having Wilson's disease. One of them had oromandibular dystonia following progressive dementia, as well as asterixis and generalized muscular rigidity. The other patient showed generalized dystonia with severe dysarthria, dementia and muscular rigidity. Both had Kayser-Fleischer rings.

One patient developed dystonia in one leg after severe closed cranial trauma with prolonged impairment of consciousness.
The patient with mitochondrial cytopathy (Table 1) developed focal dystonia in one leg which progressed to become generalized. His clinical picture was very similar to idiopathic torsion dystonia, but computerized tomography $(\mathrm{CT})$ revealed bilateral hypodensity in the putamen region. A muscle biopsy revealed "ragged-red" fibers.

A female patient with psychogenic dystonia had abnormal movements in the neck and arms. All the usual tests for symptomatic dystonia were negative. As the patient also had episodes of abnormal behavior, a psychiatric assessment was performed, and subsequently a diagnosis of hysterical neurosis was made. Psychotherapy led to gradual improvement in the abnormal movements.

Two patients with no obvious cause for symptomatic dystonia showed other abnormalities. The first, a 58 year-old male patient had focal dystonia in his left shoulder. The rest of his neurological examination was normal, except for the presence of bilateral calcification of the basal ganglia on CT scan. Analysis of CSF and routine blood tests, including calcium level, were within normal limits. The other was a 28 -year-old man with blepharospasm and cerebellar gait ataxia. His CT scan revealed cortical and cerebellar atrophy with mild ventricular dilation. Usual tests for symptomatic dystonia were negative. These findings suggested that his dystonia was probably caused by a degenerative disease (perhaps multiple system atrophy).

\section{Discussion}

Our patients were collected from two different sources. The institutional source receives patients from the National Health Service (NHS), which offers free medical assistance to the majority of the population. The patients may also be referred to us by community hospitals and private institutions working for the NHS. These patients cannot afford private medical care. For this reason, we decided to include patients from a private clinic, with a higher economic status, in order to have a more representative sample of the population of a large urban center of Brazil.

The Movement Disorders Division does not receive patients below age 12, accounting for their exclusion from our series. Our goal was to show the clinical profile of non-pediatric dystonic patients, as seen by a general neurologist dealing with adult patients.

Table 1. Clinical Profile of 46 Patients with Symptomatic Dystonia

\begin{tabular}{|c|c|c|c|c|c|c|c|c|}
\hline & \multicolumn{2}{|c|}{ Patients } & \multicolumn{4}{|c|}{ Distribution } & \multicolumn{2}{|c|}{ Age of Onset } \\
\hline & No. & $\%$ & Foc & Seg & Gen & Uni & Mean & Range \\
\hline Tardive dystonia & 16 & 34.8 & 3 & 8 & 5 & - & 35.9 & $12-61$ \\
\hline Perinatal cerebral injury & 14 & 30.4 & - & - & 11 & 3 & 3.1 & $1-10$ \\
\hline Stroke & 6 & 13.0 & 2 & - & - & 4 & 35.3 & 6.57 \\
\hline Encephalitis & 3 & 6.5 & - & - & 3 & - & 4.0 & $1-9$ \\
\hline Wilson's disease & 2 & 4.3 & 1 & - & 1 & - & 25.5 & $15-21$ \\
\hline Cranial trauma & 1 & 2.2 & 1 & - & - & - & 24.0 & 24 \\
\hline Mitochondrial cytop. & 1 & 2.2 & - & 一 & 1 & - & 14.0 & 14 \\
\hline Psychogenic & 1 & 2.2 & - & 1 & - & - & 18.0 & 18 \\
\hline Not identified & 2 & 4.3 & 2 & - & - & - & 43.0 & $28-58$ \\
\hline
\end{tabular}

$\begin{array}{lll}\text { abbreviations: } & \text { Foc-Focal } & \text { Seg-Segmental } \\ & \text { Gen-Generalized } & \text { Uni-Unilateral } \\ & \text { Mitochondrial cytop. - Mitochondrial cytopathy }\end{array}$


Tremor along with dystonia has been reported, mainly in patients having the idiopathic type. 4.5 The frequency of $19.6 \%$ of tremor in our series suggests that it might be related in some way to the pathophysiology of dystonia rather than to the underlying disease.

The most common form of symptomatic dystonia was tardive dystonia, provoked by prolonged use of neuroleptics. The average age of onset of these patients ( 35.9 years) confirms that tardive dystonia begins earlier than tardive dyskinesia as has been reported in other surveys. ${ }^{3.6}$

Deficient perinatal care in underdeveloped countries, resulting in perinatal cerebral injuries, may be a common cause of dystonic cerebral palsy. However, in this study it was not the most common cause, probably because we did not review pediatric patients and those with chorea which is commonly associated with dystonia due to perinatal cerebral injury. ${ }^{7}$ Although we encountered 2 cases of kernicterus, as far as we are aware, this condition is no longer a problem in the urban population of Brazil. There were some cases where dystonia following perinatal cerebral injuries was recorded to begin around 10 years of age, which implies that there is a relatively large time lag between brain damage and the onset of the disorder. Foley ${ }^{7}$ reported that in $35 \%$ of patients with dystonia due to perinatal cerebral injury, the disorder began after the first 3 years of life. Another report ${ }^{8}$ observed that the first manifestation of the disorder may appear as late as 14 years of age. Dystonia due to perinatal cerebral injury usually progressively worsens until a stable steady state is reached. ${ }^{9}$ This delay in manifestation of dystonia may be related to the brain maturation. Since the appearance of dystonia caused by cerebral infarction in adults can also be delayed, ${ }^{10}$ we suggest that the brain undergoes gradual structural or physiological alterations after damage. We speculate that the delayed onset of dystonia could be due to anomalous connections of newly created projections (the phenomena of sprouting) in the basal ganglia. ${ }^{8}$ Other researchers have proposed that delayed dystonias are actually idiopathic torsion dystonias that have been triggered by a cerebral anoxic insult. In other words, the trauma might act as the initiating factor but not the cause itself."

Dystonia was usually generalized in distribution in the perinatal cerebral injury cases (11 patients), while unilateral dystonia was seen in the rest ( 3 patients). Since anoxia and kernicterus affect both sides of the basal ganglia, the unilateral dystonia suggests that these patients have had localized damage, either from direct injury or vascular lesions.

Of the 6 patients with post-stroke dystonia, 2 had focal dystonia and 4 unilateral dystonia. The average age of onset in our sample was below that expected, since stroke more commonly occurs in elderly patients. However, the small number of cases does not permit conclusions about the features of stroke-induced dystonia.

The few cases that developed postencephalitic dystonia were in the lower age group. It was not possible to detect an infective agent in any of the cases. We expect that patients with generalized dystonia have bilateral lesions in the basal ganglia. However, CT scans revealed no lesions in these regions and magnetic resonance imaging was not performed. The most common recognized causes of postencephalitic dystonia are encephalitis lethargica and secondary infections seen in AIDS patients, ${ }^{12}$ but none of our three patients had evidence of these infections.
In the patient with cranial trauma, focal dystonia developed during convalescence. Focal dystonia is not rare following trauma, ${ }^{13}$ and may take up to 4 years to appear. ${ }^{14}$

One patient had hysterical neurosis (conversion reaction), an infrequent cause of dystonia. This diagnosis should be made after other alternative causes of dystonia have been discarded. Fahn et al. ${ }^{15}$ showed that temporary relief by hypnosis or use of barbiturates is not acceptable proof for conversion reaction, since patients with organic diseases may respond in a similar fashion.

In the patient with mitochondrial cytopathy differential diagnoses were Wilson's disease, Leigh's disease and anoxic encephalopathy. ${ }^{16}$ With the exception of anoxic encephalopathy all the other causes of dystonia mentioned become progressively worse, as in our patient. Wilson's disease was discarded as there was no family history, and no other associated symptoms and signs. Leigh's disease was excluded by normal blood lactate and pyruvate levels, later than usual onset, negative family history, and absence of respiratory difficulties or other neurological abnormalities. ${ }^{17}$ A juvenile manifestation of Leigh's disease was considered $^{18}$ but the diagnosis of mitochondrial cytopathy was confirmed by muscle biopsy. Recently, similarities between the juvenile manifestation of Leigh's disease and mitochondrial cytopathy have resulted in the use of the term of "Leigh's syndrome", which may be caused by mitochondrial cytopathy. ${ }^{19,20}$

In two patients we failed to identify the underlying cause. In spite of this, we are confident that they are true cases of symptomatic dystonia due to clinical and radiological changes (see results). Although a number of diseases linked to metabolic inborn errors may give rise to dystonia, ${ }^{12}$ we did not identify any in this study.

\section{ACKNOWLEDGEMENTS}

We thank Mr. Navid Tahamtani for his technical assistance in the preparation of the manuscript, and to CNPq and FINEP for the partial financial support.

\section{REFERENCES}

1. Fahn S. Concept and classification of dystonia. Adv Neurol 1988; 50: 1-8.

2. Marsden CD. Investigation of dystonia. Adv Neurol 1988; 50: 35 44.

3. Burke RE, Fahn S, Jankovic J, et al. Tardive dystonia: late-onset and persistent dystonia caused by antipsychotic drugs. Neurology 1982; 32: 1335-1346.

4. Yanagisawa N, Goto A, Narabayashi H. Familial dystonia musculorum deformans and tremor. J Neurol Sci 1972; 16: 125-136.

5. Baxter DW, Lal S. Essential tremor and dystonic syndromes. Adv Neurol 1979; 24: 373-377.

6. Gimenez-Roldan S, Mateo D, Bartolome P. Tardive dystonia and severe tardive dyskinesia. A comparison of risk factors and prognosis. Acta Psychiatr Scand 1985; 71: 488-494.

7. Foley J. The athetoid syndrome. A review of a personal series. J Neurol Neurosurg Psychiatry 1983; 46: 289-298.

8. Burke RE, Fahn S, Gold AP. Delayed-onset dystonia in patients with "static" encephalopathy. J Neurol Neurosurg Psychiatry 1980; 43: 789-797.

9. Saint-Hilaire M-H, Burke RE, Fahn S, et al. Delayed-onset dystonia following perinatal or childhood anoxia: natural history and treatment. Neurology 1988; 38 (Suppl 1): 130.

10. Grimes JD, Hassan MN, Quarrington AM, et al. Delayed-onset posthemiplegic dystonia: CT demonstration of basal ganglia pathology. Neurology 1982; 32: 1033-1035.

11. Obeso JA, Vaamonde J, Bamaquer-Bordas L. Delayed-onset dystonia. J Neurol Neurosurg Psychiatry 1985; 48: 1190-1191. 
12. Calne DB, Lang AE. Secondary dystonia. Adv Neurol 1988; 50: 933.

13. Koller WC, Wong JF, Lang, A. Post-traumatic movement disorders: a review. Mov Disord 1989; 4: 20-36.

14. Pettigrew LC, Jankovic J. Hemidystonia: a report of 22 patients and a review of the literature. J Neurol Neurosurg Psychiatry 1985; 48: 650-657.

15. Fahn S, Williams D, Reches A, et al. Hysterical dystonia, a rare disorder: report of five documented cases. Neurology 1983; 33 (Suppl 2): 161.

16. Aicardi J, Gordon N, Hagberg B. Holes in the brain. Dev Med Child Neurol 1985; 27: 249-260.

17. Pincus JH. Subacute necrotizing encephalomyelopathy (Leigh's disease): a consideration of clinical features and etiology. Dev Med Child Neurol 1972; 14: 87-101.
18. Rondot P, De Recondo J, Davous P, et al. Rigidité extra-pyramidale avec dystonie, atrophie optique et atteinte bilatérale du putamen chez un adolescent. Forme juvénile de la maladie de Leigh. Rev Neurol (Paris) 1982; 138: 143-148.

19. Marsden CD, Lang AE, Quinn NP, et al. Familial dystonia and visual failure with striatal CT lucencies. J Neurol Neurosurg Psychiatry 1986; 49: 500-509.

20. Berkovic SF, Karpati G, Carpenter S, et al. Progressive dystonia with bilateral putaminal hypodensities. Arch Neurol 1987; 44: 1184-1187. 